\title{
Ecological and developmental issues in the practice of educational psychology
}

\author{
Dr Josephine Bowler \\ Psychologist
}

\begin{abstract}
This conceptual article examines what is meant by the term 'ecological-contextual' in relation to the assessment of children's needs. Revisiting the discipline of ethology, the article applies the construct of niche to the human species, including examples from children's experiences to validate the relevance of this link. Issues of power imbalance in relationships are discussed in relation to the strategies children use to assume some control over the situations they find themselves in. It is suggested that without a comprehensive contextual analysis it becomes more likely that children's problematic behaviours will be interpreted in terms of medical categories. A range of theoretical perspectives linked to the reciprocity that characterises all relationships and the significance of such reciprocity to children's construction of meaning and feelings of selfefficacy is discussed. The hypothesis that attachment issues can become a disorder for the child is challenged. The use of the community genogram is introduced as a working tool for exploring children's multiple contexts. While the practice of educational psychology is the primary focus of this article, the dimensions discussed have equal relevance to all who work with children presenting problematic behaviours or developmental concerns. This article is intended to initiate further dialogue on these themes.
\end{abstract}

\section{Research paper}

KEYWORDS:

Attachment behaviour, child development, education psychology, ecological perspective, resilience.

\section{INTRODUCTION}

The terms ecological and ecological-contextual are often used but seldom defined except by reference to the nested systems model of Urie Bronfenbrenner (1979). Ecology is "the study of relationships between living organisms and their environment ... the set of relationships of a particular organism with its environment" (Collins 1993, p. 407). Relationships are dynamic, involving more than one person. This implies that an assessment of any child's situation should have at least two people, and often more, as the minimum unit of study. The focus may be the parentchildren dyad, the teacher-children relationship or the children in interaction with their peer group or siblings. Problematic behaviours always occur in the context of relationships.
Our sense of self, of self-efficacy, self-worth and meaning has its roots in our relationships but it is also influenced by the attributes of the current physical context in which we are embedded. As an information-processing species, we continually carry on internal dialogues with those who are significant in our world, alongside our actual verbal and physical interactions with them. Children construct meaning in internal, external, emotional, physical and social contexts, which both constrain and facilitate development.

\section{RECIPROCITY AND POWER}

When children are reared within the context of nurturing relationships the foundations are laid for developmental well-being and resilience.

Especially in its early phases, and to a great extent throughout the life course, human development takes place through processes of progressively more complex reciprocal interactions between an active, evolving biopsychological human organism and the persons, objects, and symbols in its immediate environment. To promote well-being these interactions must occur on a fairly regular basis over extended periods of time. Such enduring forms of interaction in the immediate environment are referred to as proximal processes. (Bronfenbrenner \& Ceci, 1994, p. 572).

This construct of proximal processes fits with theoretical descriptions of how learning is socially mediated in the zone of proximal development (Vygotsky, 1978). Bronfenbrenner and Ceci's summary of research on problem behaviours in early childhood, and parental monitoring of adolescent school achievement, revealed that high levels of positive interaction contributed to effective developmental functioning (p. 572). The biological-ecological model they present suggests that when reciprocity between children and significant adults does not involve a high degree of warmth and engagement "genetically based potentials for effective psychological functioning remain relatively unrealised but... become actualised to a progressively greater extent as proximal processes increase in magnitude" (p. 569). This is consistent with the theory of reaction range that suggests that although each person has a unique, genetically determined response to the environment, a favourable context can enhance performance, within the range of outcomes possible for that individual (Gottesman, 1963). It is also consistent with research on parenting styles that 
showed an authoritative approach combining high warmth with high levels of supervision from early childhood resulted in more favourable developmental outcomes in adolescence than permissive or authoritarian approaches (Baumrind, 1975, 1991).

Reciprocity, sometimes called bi-directionality, does not necessarily involve an equal power base. Basic to an ecological methodology must be some analysis of the degree of each participants' power in a particular setting in recruiting the resources perceived as necessary to their well-being.

\section{THE DEVELOPMENTAL NICHE}

In an ecological-contextual approach to the analysis of problematic behaviour insight can be gained from ethology, the study of animals in their normal environment - a term derived from the Greek ethos, meaning "character" (Collins, 1993, p. 439). The significance of ethology to psychology has been progressively demonstrated throughout the 20th century in the experiments on imprinting by Lorenz (1966) and Tinbergen (1972); the differentiation of human bonding and attachment (Ainsworth, 1991; Ainsworth and Wittig, 1969; Bowlby, 1957 and 1969) and the elaboration of attachment theory in relation to trauma (Crittendon 1988, Main 1990). To understand the antecedents of children's developmental well-being, it is necessary to examine the construct of niche that has the potential to provide educational psychology with an additional perspective for exploring an individual's situation. In a child's microsystem, as described by Bronfenbrenner, there are a series of niches occupied by each person who lives in a family or functions in other contained settings such as schools and classrooms. Niche analysis would involve examination of primary settings in greater microdetail, in the contexts of relationships.

Niche is a construct that incorporates and goes beyond the physical habitat. Ethologists, Elton (1927), Hutchinson (1965) Pianka (1983), Dennet (1983), Wallace (1987) and Archer (1992) have described properties of the niche that include competitiveness and boundary testing of the tolerance limits of available resources. Super and Harkness (1986) investigated the relevance of niche to the study of human development and behaviour, concluding "the developmental niche provides a framework for examining the effects of cultural features of child rearing in interaction with general developmental parameters" (p. 546). From the child's perspective these authors attempted to understand processes of development and acquisition of culture. They defined three aspects of the developmental niche - the physical and social settings in which the child lives, the culturally regulated customs of child care and child rearing, and the psychology of the caretakers.

These three subsystems share the common function of mediating the individual's developmental experience within the larger culture. Regularities in the subsystems, as well as thematic continuities from one culturally defined developmental stage to the next, provide material from which the child abstracts the social, affective and cognitive rules of the culture, as much as the rules of grammar are abstracted from the regularities of the speech environment. (Super \& Harkness, 1986, p. 552)

The niche defines cultural identity and both facilitates and constrains the individual's capacity for a sense of self-efficacy in that setting. It fits with Vygotsky's thesis of development as a socially and culturally mediated process, and his description of the mediating role of others in this process. The niche can be envisaged as a multidimensional interactive context of conditions and systems in which he individual is an active and reciprocal element. In this, the capacity for individuals to assume agency and power is influenced.

Children continually seek to make meaning out of the situations in which they find themselves. Their behaviours are a function of this search and make sense in some way that relates to the child's embeddedness in a particular setting, despite the fact that these behaviours may appear problematic to adults. The feedback they receive is incorporated into a growing sense of self as "bad" or "good", "helpless" or "powerful".

\section{CHILD'S MICROSYSTEMS}

Family, School, Sports group, Peer group, Church group

Child's personal life history $\longrightarrow \begin{aligned} & \text { Perceiving } \\ & \text { Processing } \\ & \text { Internalising } \\ & \text { Transforming }\end{aligned}$

Niche opportunities for functional reciprocity. Developmental resources and emotional and behaviour responses will differ
across settings.
Child
Child
Child
Child $\longrightarrow$ Custodial parent


A visualisation of the "contexture" of a child's experience as it might be at a particular developmental stage. The word contexture is used to indicate (a) the physical and emotional embeddedness of children within their contexts, (b) ongoing reciprocal relationships, expressed in the prefix con (meaning 'with) and (c) the emotional texture of the child's experience resulting from cognitive processing. These three aspects of experience constitute the niche. Children's capacity for developing resilience and a sense of self-efficacy resides in their ongoing construction of meaning in relation to events and relationships currently experienced.

\section{THE ROOTS OF RESILIENCE}

A recurring issue in the practice of educational psychology is the degree to which individual children are able to use the supports and guidance offered by adults within the microsystems of family, classroom, school and community settings. Those who are unable to recognise the utility value of such supports, or who lack support, may present challenging behaviours. The functions of these are hard for adults to understand but they may be to recruit nurturing, acceptance, or recognition of needs. The function of the niche is to promote survival and competition for resources is an intrinsic aspect of this. Such resources could be adult time and attention, affection, physical necessities, access to learning materials or comprehensible instruction. In families, schools and peer groups, children who can elicit and recruit the best of the available resources are likely to thrive. This involves learning the often undefined rules in play in each setting they inhabit and adapting accordingly. The capacity for such adaptive behaviour places children at an advantage in the same way that animals adapting to their habitat are at an evolutionary advantage. Functioning optimally across settings involves understanding a range of different rules and expectations. Learning about such properties of the niche is not always easy, especially for mobile and relocated children. Loss of any one or a combination of familiar and nurturing aspects of a child's daily life may trigger anger or grief that blocks the capacity to learn this essential information. Instead energy is invested in emotion. These losses might appear to adults to be significant, such as the loss of a parent through death or separation, or less important, such as moving school or losing a pet or a cuddly toy, but the degree and intensity of the loss is known only to the child. Resilient children are those who have learned to adapt to new circumstances quickly because they enter with a sense of self efficacy, grounded in the cumulative outcomes of reciprocally positive interactions with others. Others, less favourably grounded, have difficulty in working out the new supports available and adapting. Bowler (1997) recorded the retrospective recall of adults who had been in multiple foster care settings throughout childhood. One survivor described the difficulties of trying to behave in ways that would elicit a nurturing response from strangers.

You work hard to try to fit into a new place. You watch, adapt yourself and work hard at picking up the rules, then you work hard at changing yourself to blend in (p.188).
A recurrent theme in these narratives was the amount of energy expended by the children, firstly in learning about the properties of the new home and then in trying to produce behaviour that they hoped would elicit nurturing.

\section{SURVIVAL STRATEGIES}

In classic research on perception Gibson (1979) used the term "affordances" to describe how the niche of a particular family system offers information on opportunities to increase wellbeing. "What the child affords the mother is reciprocal to what the mother affords the infant" (p. 135). This construct of affordance relates to attachment. Because the "children" in Bowler's study were frequently moved around, they were not able to learn the affordances of each new setting and were seen as "cuckoos", continually ejected. Where there were biological offspring already in residence, the process of ejection was faster, probably because in evolutionary terms competition for resources means that parents must inevitably favour their natural children. One child in the Bowler study who was told that she could call the new caregiver mother, was so relieved that she allowed her feelings to surface for the first time in four years. She had constructed meaning that involved a set of expectations associated with the word mother. Thinking she was at last safe, she began to cry on the woman's bed in an attempt to seek proximity to her new caregiver. The function of this outwardly problematic behaviour was not understood and after three weeks of crying she was considered too difficult to manage and was again moved on.

I thought because she said I could call her mother that she was going to be one. Looking back I see that I got nothing from her (Bowler, 1997, p. 192).

The children in this study developed strategies aimed at meeting their needs that were often misinterpreted by unfamiliar adults as anti-social behaviours.

The child who has exhausted all the nurturing response strategies of a caregiver is no longer able to be reared effectively in that setting and is seen as requiring relocation by professionals who are progressively distant from information relating to the child's earlier niche experience. Similarly, when a child exhausts all the nurturing strategies of a biological parent, the outcome may be that the parent seeks a classification of the child's behaviours and intervention in the form of medication. Just as other species use camouflage, children use strategies to protect themselves emotionally, as another participant in the Bowler study revealed.

I was taken to this official looking place but I never batted an eyelid so no-one ever knew what was going on inside me. I instinctively knew that my body language and any words I spoke would give me away and that if I let my feelings show it would have no effect. I was hysterical inside myself with the let-down and pain but outside I was concrete and stone (Bowler, 1997, p. 191). 
This response parallels the physiological stress encountered by any other species in unfamiliar territory. While this child had an inhibitory response, another might demonstrate the distractible and seemingly random behaviour that results from a high level of central nervous system excitation. Without an historical and contextual analysis it would be easy to confuse highly aroused behaviour resulting from perceived threat with the criteria applied to children for purposes of clinical diagnosis, such as Attention Deficit Hyperactivity Disorder, or Conduct Disorder. Children who perceive threat, whose nervous system is primed for fight or flight but are powerless to deflect the danger, or move outside its range of impact, are cornered. Triggered anxiety needs to be kept within the survival limits of the body's system and managed in the tolerance limits of the niche. In the face of such threat children use the strategies they think will best serve them to have some control over their situation.

By eight I started switching off. You avert your gaze and will look anywhere except at them. You don't want to see what's written on their face. You can hear it. You can feel it. That's when you start to close down even though the fear's out. (Bowler, p. 191)

This same child stated that even being abused was better than going into another home because of all the emotional energy required in learning the properties of each new residence and trying to use these in ways that were rewarded.

\section{TAKING BACK CONTROL}

Reciprocity is basic to the concepts of affordance and niche and is also central to the construct of attachment, defined by John Bowlby as "an active, affectionate, reciprocal enduring relationship between two people whose interaction continues to strengthen their bond" (cited in Papalia \& Olds, 1998, p. 159). All attachments are persistent and enduring, whether secure or anxious and insecure in type as defined by the research of Ainsworth. By virtue of its definition, attachment cannot be redefined as the property of the individual and it becomes difficult to accept the hypothesis that attachment issues can become a disorder in the child. Attachment theory encompasses the concept of an internal working model of self in relation to others - a cognitive representation used to predict, interpret and plan for survival (Bretherton, 1996, p. 24-25). After the little girl who cried on her new caregiver's bed realised she was not going to be "mothered", she developed an internal working model of herself as the only person in her world who could be relied on.

At seven I walked up the path to yet another home in disbelief at being given away again but no-one ever knew what I was feeling. People saw me as difficult because I didn't show my feelings. I fought and fought to take care of myself and to analyse what was happening to me (Bowler, 1997, p. 191).

\section{IDENTIFYING SIGNIFICANT ASPECTS OF NICHE}

Recruiting resources in a new context, whether these are cuddles, food or teacher time, may require a range of adaptive responses that lie outside the child's current cognitive understandings and response repertoire. Super (1981) concluded that environmental objects such as mats, cribs and toys, combined with the social environment of caretakers and companions, structured the infant's opportunities for developing emergent behavioural potentials. The emotional value of even a small part of a physical environment is known only to the child.

Once when I was moved on the woman kept my dolls. When I unpacked I was upset and confused...I wondered why she'd done it (Bowler, p.188).

Linking attachment with Vygotsky's theory and Bronfenbrenner and Ceci's construct of proximal processes provides us with an understanding of the complexity of human development. There is an endless cycle of exploration and feedback as the individual learns about the physical, cultural, social and emotional properties of the ecological niche in order to grow, learn and thrive. In applying the construct of niche to cognitive functioning, one study made the point that researchers may attempt interventions designed to "enhance processes that may be well-understood in the abstract or in laboratory contexts but are poorly understood in relation to everyday practices" (Gauvain, 1995, p. 42). A theoretical framework using multisystemic units of analysis provides opportunities to examine the influence of dynamic aspects of the niche within these settings relevant to the presenting problem (Annan, 2005). Such information can help explain the functions of the child's behaviours but this is not always easy information to obtain when a family is geographically mobile. An understanding of a child's previous relationships and reinforcement history can further inform intervention. Life history relevant to a referral issue may include information about personal crises such as experience of war, famine, abuse, deprivation, illness or accident.

\section{AVOIDING DE-CONTEXTUALISATION}

The term "goodness of fit" was used by Scarr and McCartney (1983) to describe the genes-environment match of children to their family context. They suggested that as children develop and extend their range of experiences and environments they actively seek environments that fit with their genotype and temperament - an activity they called "niche-picking". In this way children and adolescents attempt to overcome power imbalances in their current relationship contexts. The research by Super outlined the relevance of niche factors to a consideration of the child's cultural setting. In New Zealand/Aotearoa an increasingly diverse ethnic population heightens the need for practitioners to establish not only appropriate bicultural practice but the significance of cultural factors in any and all problem analysis. RigazioDiGilio, Ivey, Kunkler-Peck and Grady (2005) describe how community genograms can be used to determine cultural 
influences as well as the power dynamics within families and communities. The community genogram is a tool that can be used for both assessment and intervention. In partnership with the person involved, it explores and reveals an individual's cultural physical and emotional contexts, social networks, past and present, as well as anticipated future contexts, and the value placed on each of these dimensions.

The community genogram is derived from two concepts. First, the term genogram is used to reinforce the importance of family legacies on physical and psychological development...In traditional models of counselling and therapy these legacies are often only examined in a decontexualised fashion. To place those legacies within the wider dynamic generated by interaction with peer, ethnic, religious and professional networks, the second concept of community is added (Rigazio-DiGilio et al., 2005, p. 2).

As described by these authors, the community genogram has the potential to become a flexible working tool for exploring some aspects of niche, increasing the ecological aspect of assessment relevant to the practice of educational psychology. Rigazio-DiGilio et al provide a number of visual exemplars suggesting how the community genogram could be adapted to work with children, adolescents and adults.

To ignore the dimension of niche can lead to gross misunderstandings through the decontextualization of participants' situations. A dramatic example is an historic 20th century incident involving an Australian Aboriginal community relocated to a tribal housing area development. Confined for the first time in houses, they removed the walls to access the outside environment that held all that was necessary to them for physical survival and emotional health. Not surprising for these times, this response was not interpreted by the authorities in ecological terms but served to reinforce racial stereotypes. Any immigrant community might be expected to attempt to recover lost niche affordances, whether through backyard ovens, the opening of shops selling particular foods or publications in the language of origin. The long-term implications of loss of niche are further illustrated by the situation of the unescorted children Britain removed from their families during World War II and sent to New Zealand and other Commonwealth countries to live with strangers, on the mistaken assumption they would experience nurturing and a similar culture. Fifty years later these New Zealand immigrants formed an association to deal with unresolved issues of loss.

\section{SUMMARY}

The developmental significance of an ecological approach lies in its potential to encompass all the domains of human development. While physical interactions characterise niche embeddedness, the cognitive and emotional domains are enmeshed in children's interactions with the resources of the environment. The reciprocity and totality of these interactions forms the individual's cognitive, emotional, social and cultural context and all this experience impacts cumulatively on learning and well-being. While niche analysis is a more complicated business than using standardised tests, checklists, or the verbal reports of adults, it should at least be attempted if any problem analysis is to be truly ecological.

Examples suggest that at least three relevant aspects of niche can be elicited during the process of an assessment. These are:

- the degree of power children have over their situations and their capacity to effect change,

- the emotional significance of places, objects and activities and the degree to which loss of valued dimensions relating to these has occurred, and/or might be recovered,

- the child's characteristic mode of relating to situations and contexts that trigger anxiety, along with their opportunities and facility for learning new strategies.

The challenge in the practice of educational psychology is the further development of information-gathering frameworks and models to facilitate microanalysis of the child's contexts as they impact upon learning and development. This is not a challenge confined to educational psychologists. The discussion in this article is intended to encourage dialogue among all those who work within an contextual fieldwork model over what is involved in a real, versus espoused, ecological approach to the assessment of children's needs. Such dialogue has the potential to further inform developmentally and culturally relevant interventions across settings.

\section{REFERENCES}

Ainsworth, M. D. (1991). Attachments and other affectional bonds across the life cycle. In C. Parkes, J. Stevenson-Hinde, \& P. Marris, (Eds.) Attachment across the life cycle. London: Routledge.

Ainsworth, M.D.S. \& Wittig, B. (1969). Attachment and exploratory behaviour of one-year-olds in a strange situation. In B. M. Foss (Ed.) Determinants of infant behaviour, Volume 4. (pp. 111-136). NY: Wiley.

Annan, J. (2005). Situational analysis: A framework for evidence-based practice. School Psychology International, 26,131-146.

Archer, J. (1992). Ethology and human development. Maryland: Barnes and Noble Books.

Baumrind, D. (1975). Early socialisation and the discipline controversy. Morrristown, NJ: General Learning Press.

Baumrind, D. (1991). Parenting styles and adolescent development. In R. M. Learner, A.C. Petersen \& J. BrooksGunn (Eds.) Encyclopedia of adolescence. New York: Garland.

Bowlby, J. (1957). An ethological approach to research in child development. British Medical Journal, 30, 230-240. 
Bowlby, J. (1969). Attachment and loss. Vol. 3. New York: Basic Books.

Bowler, J. (1997). Over a cricket's grave: Retrospective attachment experience in long-term foster care. In Adoption and healing (pp. 183-194). Proceedings of the International Conference on Adoption and Healing: Wellington, New Zealand.

Bretherton, I. (1996). The roots and growing points of attachment theory. In C. Parkes, J. Stevenson-Hinde \& P. Marris (Eds.) Attachment across the life cycle. London: Routledge.

Bronfenbrenner, U. (1979). The ecology of human development: Experiments by nature and design. Cambridge, Mass: Harvard.

Bronfenbrenner, U. \& Ceci, S. J. (1994). Nature-Nurture reconceptualized in developmental perspective: $\mathrm{A}$ bioecological model. Psychological Review, 4, 568-586.

Collins Concise English Dictionary (3rd ed.), (1993). Glasgow: Harper-Collins.

Crittendon, P. (1988). Maternal antecedents of attachment quality. In J. Belsky and T. Nezworski (Eds) Clinical implications of attachment. Hillsdale, NJ: Eilbaum.

Dennet, D. C. (1987). The intentional stance. Cambridge, Mass: MIT Press.

Elton, C. S. (1927). Animal ecology. London: Sidgwick \& Jackson.

Gauvain, M. (1995). Thinking in niches: Socio-cultural influences on cognitive development. Human Development, $38,25-45$

Gibson, J. J. (1979). The ecological approach to visual perception. Boston: Houghton Mifflin

Gottesman, I. (1963). Genetic aspects of intelligent behaviour. In N. Ellis (Ed.), Handbook of mental deficiency. (pp. 253296). New York: McGraw-Hill

Hutchinson, G. E. (1965). The ecological theatre and the evolutionary play. New Haven: Yale University Press.

Lorenz, K. (1966). Evolution and modification of behaviour. London: Methuen.

Main, M. (1990). A typology of human attachment organisation, assessed with discourse, drawings and interviews. New York: Cambridge University Press.

Papalia, D., Olds, S. \& Feldman, R. (1998). Human Development (7th ed.). Boston, Mass: McGraw-Hill.

Pianka, E. R. (1983). Evolutionary ecology (3rd ed.). NY: Harper and Row.

Rigazio-DiGilio, S., Ivey, A., Kunkler-Peck, \& Grady, L. (2005). Community genograms: Using individual family and cultural narratives with clients. NY: Teacher's College Press.
Scarr, S. \& McCartney, K. (1983). How people make their own environments: A theory of genotype environment effects. Child Development, 54, 424-435.

Super, C. M. (1981). Behavioural development in infancy. In R. H. Munroe, R. L. Munroe, \& B. B. Whiting (Eds) Handbook of cross-cultural human development, (pp. 181-270). NY: Garland.

Super, C. M. \& Harkness, S. (1986). The developmental niche: A conceptualisation at the interface of child and culture. International Journal of Behavioural Development, 9 , 545-569.

Tinbergen, N. (1972). The animal in its world. London: Allen and Unwin.

Vygotsky, L. S. (1978). Mind in society: The development of higher psychological processes. (M. Cole, Ed.) Cambridge: Harvard University Press.

Wallace, A. (1987). The niche in competition and evolution. NY: John Wiley.

\section{AUTHOR PROFILE}

Dr Josephine Bowler is currently working as a relieving psychologist with GSE. She left Massey University in 2005 after 10 years as a lecturer in the College of Education. She was formerly a teacher and, after graduating as an educational psychologist in1980, worked in South Auckland and on the North Shore. She has a PhD in education and is also a published children's poet. 